\title{
LA DIMENSIÓN CONSTITUCIONAL DEL PRINCIPIO DE CONTRADICCIÓN Y SUS REFLEJOS EN EL DERECHO PROBATORIO BRASILEÑO*
}

Darci Guimarães Ribeiro ${ }^{* * *}$

\begin{abstract}
RESUMEN
La contradicción en el derecho brasileño reviste una gran importancia, de ello da muestra la Constitución Federal, en la que se propende por la igualdad de las partes al acceder al proceso. Aunque el principio de la contradicción debió ceder terreno a finales del siglo XIX, en razón a la moderna exigencia legal de la efectividad de la prestación jurisdiccional, desde mediados del siglo XX adquiere nuevamente su valor. El recorrido sobre la evolución de este principio, permite demostrar la íntima conexión que existe entre este y la prueba.
\end{abstract}

Palabras clave: Principios procesales, contradicción, prueba, efectividad de la prestación jurisdiccional.

Fecha Recibido: abril 12 de 2014 - Fecha Aceptado: julio 14 de 2014

* Artículo inédito.

** Abogado. Posdoctorado por la Università degli Studi di Firenze. Doctor en Derecho por la Universitat de Barcelona. Especialista y Master por la Pontifícia Universidade Católica do Rio Grande do Sul (PUC/RS). Profesor Catedrático de Derecho Procesal Civil de la UNISINOS y PUC/RS. Profesor del Programa de Posgrado en Derecho de la UNISINOS (Master, Doctorado y Posdoctorado). Miembro del Instituto Brasileño de Derecho Procesal Civil. Miembro de la Academia Brasileña de Derecho Procesal. Miembro del Instituto Iberoamericano de Derecho Procesal Civil. Miembro de la International Association of Procedural Law. Miembro representante del Brasil en el Proyecto Internacional de Investigación del Ministerio de Educación y Cultura -MEC- de España. 


\begin{abstract}
The principle of contradiction in Brazilian law has paramount importance. The Federal Constitution proves that, searching the equality of the parties to access at the process. Although the principle of contradiction must give ground in the late XIX century, due to modern legal requirement for the effectiveness of judicial protection, since the mid XX century acquired its value again. The study of the evolution of this principle demonstrates the intimate connection between the contradiction and the proof.
\end{abstract}

Kew words: Procedural principles, contradiction, proof, judicial protection.

\title{
1. El PRINCIPIO de CONTRAdicCión EN EL ESTADo CONSTITUCIONAL
}

Este principio también es conocido como principio de la bilateralidad de la audiencia ${ }^{1}$ o, como prefieren los alemanes, el derecho a ser oído legalmente ${ }^{2}$, o simplemente igualdad ${ }^{3}$, traducido en el brocardo latino como audiatur et altera pars. Se trata este de una garantía fundamental de la justicia, elevado en dogma constitucional en la mayoría de los países y se manifiesta, también, como un principio del Estado de Derecho ${ }^{4}$. Podemos encontrarlo en la Costituzione

1 WYNESS MILLAR, Robert. Los principios formativos del procedimiento civil. Trad. Catalina Grossmann. Buenos Aires: Ediar, 1945, p. 47.

2 Conforme art. 103, I de la Grundgesetz (Ley Fundamental de la República Federal de Alemania) que dice: "Articulo 103 (Derechos fundamentales del acusado) 1. Todos tienen el derecho de ser oídos ante los tribunales; (...)".

3 COUTURE, Eduardo J. Fundamentos del derecho procesal civil. Buenos Aires: Depalma, 1988, p. 183. Sobre las relaciones entre el principio de contradicción y el principio de igualdad de armas (Waffengleichheit), consultar NELSON NERY JUNIOR, Princípios do Processo Civil na Constituição Federal. São Paulo: RT, 2013, p. 255 e 256.

4 En este particular, conviene destacar las palabras de OTHMAR JAUERNIG, para quien el derecho a ser oído es el " princípio processual mais importante' e elemento irrenunciável de todo o ordenamento processual de Estado de Direito, (...)", Direito Processual Civil. Trad. F. Silveira Ramos. Coimbra: Almedina, 2002, $\$ 29$, p. 167 y, también, de STEFAN LEIBLE, según las cuales "El Tribunal Federal de Constitucionalidad lo deriva del principio de Estado de Derecho (art. 20 párr. 3 LF, 28 párr. 1). (...) También es propio de un procedimiento justo, que se le dé en general oportunidad a las partes de expresarse. El derecho a ser oído legalmente, es decir a ser oído por el juez, es por ello el más importante principio procesal y una parte irrenunciable de todo orden procesal de un Estado de Derecho", Proceso Civil Alemán. Trad. Rodolfo E. Witthaus. Colombia: Biblioteca Jurídica Diké e Konrad Adenauer Stiftung, 1999, p. 152 e 153. En el Brasil, igualmente sostiene esta idea, NELSON NERY JUNIOR, Princípios do Processo Civil na Constituição Federal, RT, 2013, n 24, p. 220. 
della Repubblica Italiana, art. 24, 20 ${ }^{\circ 5}$; en la Constitución Española, art. 24, $1^{6}$, en la Grundgesetz, art. 103, 17 , bien como en el art. $6^{\circ}$ de la Convention Européenne des Droits de L'Homme que trata del Droit à un procès équitable ${ }^{8}$. En el Brasil, este principio tiene amparo en el núm. LV, del art. $5^{\circ}$ de la Constitución Federal ${ }^{9}$. Caba destacar que, en Brasil, este principio constitucional está expresamente extendido al proceso administrativo ${ }^{10}$.

5 “(...) La difesa è diritto inviolabile in ogni stato e grado del procedimento. (...)”. El propio Codice di procedura civile Italiano, en su art. 101, define el principio de contradicción, cuando dice expresamente: "Il giudice, salvo che la legge disponga altrimenti (p. c. 633, 697, 700, 703, 712), non può statuire sopra alcuna domanda, se la parte contro la quale è proposta non è stata regolarmente citata (p. c. 164) e non è comparsa (p. c. 181, 291)". Ese principio es tan influyente en la legislación italiana que, en el proceso de ejecución forzada, el juez de la ejecución, regla general, no puede dictar ninguna medida judicial sin antes oír las partes, e. g., arts. 530, 552, 569, 590, 596, 600, 612 e 624.

$6 \quad$ "1. Todas las personas tienen derecho a obtener la tutela efectiva de los jueces y tribunales en el ejercicio de sus derechos e intereses legítimos, sin que, en ningún caso, pueda producirse indefensión. 2. Asimismo, todos tienen derecho al Juez ordinario predeterminado por la ley, a la defensa y a la asistencia de letrado, a ser informados de la acusación formulada contra ellos, a un proceso público sin dilaciones indebidas y con todas las garantías, a utilizar los medios de prueba pertinentes para su defensa, a no declarar contra sí mismos, a no confesarse culpables y a la presunción de inocencia. (...)".

7 "1. Todos tienen el derecho de ser oídos ante los tribunales; (...)", Cinqüenta Anos de Jurisprudência do Tribunal Constitucional Federal Alemão. Org. Leonardo Martins. Montevideo: Fundación Konrad-Adenauer, 2005, p. 913.

$8 \quad$ "Toda persona tiene derecho a que su causa sea oída equitativa, públicamente y dentro de un plazo razonable, por un Tribunal independiente e imparcial, establecido por ley, que decidirá los litigios sobre sus derechos y obligaciones de carácter civil o sobre el fundamento de cualquier acusación en materia penal dirigida contra ella. (...)". Sobre la Corte Europea de los Derechos Humanos, consultar www.echr.coe.int/

9 "LV - Aos litigantes, em processo judicial ou administrativo, e aos acusados em geral são assegurados o contraditório e ampla defesa, com os meios e recursos a ela inerentes".

10 Con base en la redacción del texto constitucional podemos fácilmente percibir que este principio se aplica tanto al proceso judicial como al proceso administrativo y más, a todos los acusados en general fuera de los límites de los procesos judiciales o administrativos. A respeto de este principio en el proceso administrativo, el Supremo Tribunal Federal de Brasil ya afirmó que "A decisão ora agravada reflete a pacifica jurisprudência desta Corte a respeito do tema, que reconhece a necessidade da observância dos princípios do contraditório e da ampla defesa em procedimento de dispensa de servidor público. Esses postulados devem ser seguidos ainda que se trate de servidor contratado sob o regime celetista e mesmo que ainda se encontre em fase de estágio probatório." (AI 634.719-ED, Rel. Min. Dias Toffoli, julgamento em 7-2-2012, Primeira Turma, DJE de 9-3-2012.), Constitución Comentada por el STF, in http:// www.stf.jus.br/arquivo/cms/publicacaoLegislacaoAnotada/anexo/Completo.pdf, consulta en 10.07.2014. Pero, la necesidad de aplicación de este principio al proceso administrativo no implica en la obligatoriedad de una defensa técnica por un abogado, según la sumula vincu- 
Ese principio es tan esencial en el derecho brasileño que la propia Constitución Federal procura igualar la condición de acceso al proceso a las partes, dando en provecho de aquellos que no dispongan de recursos para los gastos de la demanda, los favores de la asistencia judiciaria gratuita ${ }^{11}$, núm. LXXIV, del art. $5^{\circ}$ de la Constitución Federal ${ }^{12}$, sea a través de la defensoría pública, art. 134 da Constitución Federal ${ }^{13}$, o no. Pero, no se puede negar que desde mucho tiempo este principio tiene insistentemente cedido lugar a una nueva exigencia legal surgida con la modernidad: la efectividad de la prestación jurisdiccional.

La desvalorización del principio de contradicción comienza a partir del final del siglo XIX, según el valioso estudio de PICARDI, vez que el espirito positivista impone "o exaurimento da função axiológica do princípio do contraditório"14.

lante $\mathrm{n}^{\circ} 5$ del Supremo Tribunal Federal que dice: "A falta de defesa técnica por advogado no processo administrativo disciplinar não ofende a Constituição".

Sobre el proceso administrativo cumple señalar que en el derecho italiano el principio de contradicción también se aplica a este proceso, según art. 24, 2 y 11, 2 de la Constitución Italiana y está expreso en términos generales en el art. 101 del Código Procesal Civil de Italia, según MARCELLO CLARICH, La giustizia. In: Trattato di Diritto Amministrativo. Coord. Sabino Cassese. Milano. Giuffrè, 2003, T. II, n 2.5.3, p. 2.139. Para este autor, " $A$ differenza di quanto accade nel processo civile, nel processo amministrativo il contraddittorio e' sempre anticipato (anche per cio ' che riguarda la tutela cautelare, in relazione alla quale, come si e visto, non e' ammessa la tutela ante causam)", Op. cit., p. 2.139.

11 En el Brasil, la asistencia judiciaria gratuita está prevista en la ley $n^{\circ}$ 1.060/1950. Sobre la asistencia judiciaria en el derecho brasileño, consultar la obra de ÂNGELO MARANINCHI GIANNAKOS, Assistência Judiciária no Direito Brasileiro, Porto Alegre: Livraria do Advogado, 2008. En Colombia, el actual Código General del Proceso, Ley 1564 de 2012, en su artículo 10, prevé que: "Artículo 10. Gratuidad. El servicio de justicia que presta el Estado será gratuito, sin perjuicio del arancel judicial y de las costas procesales”. En el igual sentido del texto JORGE PEYRANO, El Proceso Civil. Buenos Aires: Astrea, 1978, p. 148. El conocido autor rosarino incluso sostiene incorporar "legalmente soluciones derivadas del referido concepto de 'socialización del proceso civil”, para, puntualmente, corregir distorsiones del sistema, Op. cit., p. 151.

12 "LXXIV - o Estado prestará assistência jurídica integral e gratuita aos que comprovarem insuficiência de recursos". En España, así como en el Brasil, este instituto también está expreso en la Constitución, art. 119: "La justicia será gratuita cuando así lo disponga la ley y, en todo caso, respecto de quienes acrediten insuficiencia de recursos para litigar". También en la Ley de Enjuiciamiento Civil no 1/2000, art. 394, III, 3, y principalmente en la Ley de Asistencia Jurídica Gratuita, n 1/1996, de 10 de enero, alterada en 23 de febrero de 2013.

13 “Art. 134. A Defensoria Pública é instituição essencial à função jurisdicional do Estado, incumbindo-lhe a orientação jurídica e a defesa, em todos os graus, dos necessitados, na forma do art. 5', LXXIV".

14 Audiatur et altera pars. As matrizes históricos-culturais do contraditório. In: Jurisdição e processo. Coord. Carlos Alberto Álvaro de Oliveira. Trad. por Luís Alberto Reichelt. Rio de Janeiro: Forense, 2008, p. 137. 
Sin embargo, a partir de la mitad del siglo XX, este principio vuelve a ser revalorizado, especialmente a través de Carnelutti ${ }^{15}$, Satta ${ }^{16}$ y especialmente Fazzalari ${ }^{17}$, en la medida en que quedó evidenciado, aún más, el carácter dialéctico, dialógico del proceso, en una relación simbiótica entre partes y juez. Desde esta perspectiva, pues, es oportuno destacar la acertada advertencia realizada por Carlos Alberto Alvaro de Oliveira, según la cual el principio de contradicción es "um poderoso fator de contenção do arbítrio do juiz"18.

\section{LA DIALÉCTICA PROCESAL Y EL CONTRADICTORIO}

El referido principio presenta como característica el hecho de que el juez, teniendo el deber de ser imparcial, no puede juzgar la demanda sin que tenga antes oído actor y reo, o sea, deberá conceder a las partes la posibilidad de que expongan sus razones con la ayuda de la prueba y conforme su derecho, pues, doctrina Chiovenda: "Como quem reclama justiça, devem as partes colocar-se no processo em absoluta paridade de condições"19. Eso trae como consecuencia necesaria la igualdad de tratamiento entre las partes, en todo el curso del proceso, no limitándose solamente a la formación de la litis contestatio ${ }^{20}{ }^{21}$.

15 Torniamo al giudizio. In: Rivista di Diritto Processuale Civile, 1949, p. 168 y ss.

16 Para quien el proceso "non è altro che giudizio e formazione di giudizio", Il mistero del processo. In: Rivista di Diritto Processuale Civile, 1949, p. 281. También publicado en el libro Soliloqui e Colloqui di un Giurista, Nuoro: Ilisso, 2004, p. 45.

17 Diffusione del processo e compiti della doctrina. In: Rivista Trimestrale di Diritto e Procedura Civile, 1958, p. 861 e ss. La idea central de este autor, hoy bastante difundida, es aquella según la cual el proceso nada más es que el procedimiento en contradicción. Do formalismo no processo civil, São Paulo: Saraiva, 2009, 3ª ed., nº 14.4, p. 133.

19 Instituições de direito processual civil. Trad. J. Guimarães Menegale. São Paulo: Saraiva, 1969, $1^{\circ}$ vol., $\mathrm{n}^{\circ} 29, \mathrm{p} .100$.

20 En ese sentido, JORGE PEYRANO, El Proceso Civil, Op. cit., p. 146 y EISNER, Principios Procesales. In Revista de Estudios Procesales, n 4, p. 53.

21 Sobre la litis contestatio, conviene destacar que en el período formulario, para llegar a la condemnatio, las partes deberían realizar antes un pacto procesal delante de testigos denominado litis contestatio (litis es igual a litigio, y con-testatio es igual a 'con testigos', ya que, según IHERING, testis significa "el que asiste", (El espíritu del derecho romano. Trad. de Enrique Príncipe y Satorres. Granada: Comares, 1998, t. I, $\$ 13$, p. 115). De ese modo, litis contestatio significa, de acuerdo con SCIALOJA, "invocar testigos para que certifiquen la existencia de la litis y el contenido de ella”, (Procedimiento civil romano. Trad. de Santiago Sentís Melendo e Marino Ayerra Redin. Buenos Aires: EJEA, 1954, $\mathbb{1} 15$, p. 157), que era el punto culminante y la esencia misma de esa forma de procedimiento. Para ROYO, el pacto procesal (litis contestatio) incluya acuerdos sobre: "El juez que habría de dictaminar; la aceptación previa de la sentencia y la definición del asunto que enfrentara a las partes: la aportación de los datos en 
Es lo que se deprende del caput del art. $5^{\circ}$ de la Constitución Federal de Brasil cuando la misma declara expresamente que "Todos são iguais perante à lei, (...)", bien como del art. 125, I del Código Procesal Civil Brasileño y de los arts. $7^{\circ}$ y $9^{\circ}$ del proyecto del nuevo $\mathrm{CPC}^{22}$. Empero esa igualdad entre las partes, en el decir de COUTURE, "no es una igualdad numérica, sino una razonable igualdad de posibilidades en el ejercicio de la acción y de la defensa" ${ }^{23}$.

La importancia de ese principio está directamente relacionada a la dialéctica del proceso y al concepto de litis ${ }^{24}$. Cuanto a la dialéctica es sabido que el proceso

que cada uno apoyara la calidad de su poder sobre el asunto controvertido y sus implicaciones. Como consecuencia del acuerdo de las partes, el pretor habría de redactar un pequeño documento conocido como 'formula'. De ese documento se puede afirmar con seguridad que se trata de: a) una orden imperativa del pretor dirigida al elegido como juez mediante la que le ordena: - que actúe como juez en ese caso, - que condene o no a una de las partes en función de la investigación (prueba) de los hechos que subyacen al conflicto; b) un escrito cuya estructura sintáctica es igual a la de la norma abstracta; c) una norma substantiva para las partes en cuanto incluye las afirmaciones, excepciones y argumentos contradictorios incluidos en el acuerdo de la 'litis contestatio'; y d) una orden de condena o no, según un criterio alternativo: - sea a la devolución de cosa o a una actividad en favor de la otra parte (...), - sea al pago de una cantidad de dinero: o concreta, fijada previamente, o a concretar según apreciación del juez", (Palabras con poder. Barcelona: Marcial Pons, 1997, cap. IV, p. 96 y 97). Una vez realizado el pacto procesal delante de testigos, el juez debería únicamente decir el derecho, pues, de acuerdo con la opinión de IHERING, "el juez del derecho antiguo no impone nada al demandado, no le da ninguna orden en nombre del Estado: no hace más que dar a las partes el auxilio de sus conocimientos jurídicos. El idioma ha expresado exactamente la relación que existe entre la acción del juez y la del demandante. El juez debe únicamente decir el derecho ('dicere'); de aqui su nombre de 'judex', y lo hace dando su consejo ('sententia')", (El espíritu del derecho romano, Op. cit., t. I, $\$ 15$, p. 137. Pues, según el autor, “la raiz 'dic' significa en latín, como en sánscrito y en griego (deicunmi), señalar, mostrar (por ejemplo, 'dicis causa, digitus, indicare'); 'dicere', decir, es mostrar verbalmente", (El espíritu del derecho romano, Op. cit., t. I, $\mathbb{\$} 14$, p. 129 , nota 109. Para profundizar mejor en el estudio de la influencia de la litis contestatio en las diversas legislaciones, principalmente la española, Cfr. por todos, FAIRÉN GUILLÉN, El juicio ordinario y los plenarios rápidos. Barcelona: Bosch, 1953, principalmente pp. 35 y ss.

22 "Art. $7^{\circ} . \dot{E}$ assegurado às partes paridade de tratamento no curso do processo, competindo ao juiz velar pelo efetivo contraditório" y "Art. $9^{\circ}$. Não se proferirá decisão contra uma das partes sem que esta seja previamente ouvida. Parágrafo único. O disposto no caput não se aplica: $I-\grave{a}$ tutela antecipada de urgência; II - às hipóteses de tutela antecipada da evidência previstas no art. 306, incisos II e III; III - à decisão prevista no art. 716". Informe Final de la Cámara de los Diputados, presentado por el Diputado Paulo Teixeira en 26.03.2014, del Proyecto de Ley ${ }^{\circ}$ 8.046, de 2010.

$23 \quad F u n d a m e n t o s$ del Derecho Procesal Civil. Buenos Aires: Depalma, 1988. n 116, p. 185.

24 La litis como característica de la jurisdicción fue creada por CARNELUTTI. Dentro de las obras doctrinarias de CARNELUTTI, podemos distinguir, en ese particular, dos fases: la primera en que el autor entendía como jurisdiccional tanto el proceso de declaración, como 
contemporáneo es un proceso de partes ${ }^{25}$, donde hay una tese (afirmación del actor), una antítesis (negación del reo) y, finalmente, una síntesis (sentencia del juez). De ahí la importancia de las partes, sea para iniciar y fijar los límites de la controversia, sea para desenvolverla, a punto de Carnelutti demonstrar que "es un hecho que "las partes no son juzgadas si no ayudan a juzgar" 26 , tanto por las pruebas que presenten cuanto por el comportamiento que desarrollan; esta es la razón por la cual se dice que las partes, en relación al juez, no tienen papel de antagonistas, sino de colaboradoras ${ }^{27}$. Y, en el que dice respecto a la

el proceso de ejecución, porque, según su concepto, la resistencia es el elemento que califica la litis, y esa puede discutir o lesionar la pretensión, generando, por consiguiente, una pretensión discutida o una pretensión insatisfecha, en el primer caso estamos delante del proceso de declaración y, en el segundo, delante del proceso de ejecución, (Sistema de derecho procesal civil. Trad. Niceto Alcalá-Zamora y Castillo e Santiago Sentís Melendo. Buenos Aires: Uthea, 1944, v. II, no 124, p. 12, así como Instituciones del nuevo proceso civil italiano. Trad. de Jaime Guasp. Barcelona: Bosch, 1942, v. I, n 9, p. 34). El autor confirma esta idea en su conocida discusión con Calamandrei, al decir que existe litis "quando taluno pretende la tutela di un suo interesse in contrasto con l'interesse di un altro e questi vi resiste mediante la lesione dell'interesse o mediante la contestazione della pretesa", (Lite e processo. In: Studi di Diritto Processuale. Padova: Cedam, 1939, p. 29). Posteriormente, en su segunda fase, cuando escribió su magnífica obra intitulada Diritto e Processo, en el año de 1958, trajo para dentro de la jurisdicción el proceso voluntario, diciendo literalmente: "La jurisdicción voluntaria 'es verdaderamente jurisdicción' resulta tanto del fin como del medio: del fin, porque ella constituye, lo mismo que la jurisdicción contenciosa, un remedio contra la desobediencia, aun cuando en potencia más bien que en acto; del medio, porque la reacción se cumple mediante la declaración de certeza, respecto de la cual ya sabemos que consiste en una elección oficial que se sustituye a la elección del particular; y precisamente en una elección hecha super partes y por eso imparcial", (Derecho y processo. Trad. de Santiago Sentís Melendo). Buenos Aires: EJEA, 1971, n 37, p. 74). Para analizar detalladamente las diversas críticas sobre esta visión 'funcional' de la jurisdicción, consultar lo que escribí en La pretensión procesal y la tutela judicial efectiva, Barcelona: Bosch, 2004, n 2, nota 38, p. 30.

25 Esa concepción tuvo origen en la Revolución Francesa, en la medida en que los poderes de los magistrados fueron reducidos y, por consiguiente, hubo un aumento de los poderes de las partes, conforme apunta MERRYMAN, La Tradición Jurídica Romano-Canonica. México: Fondo de Cultura Económica, 1994, p. 78. Actualmente con la influencia del Estado Democrático de Derecho en el proceso esta visión viene ganando cada vez más fuerza. En ese particular conviene citar por todos la obra de DIERLE NUNES, Processo jurisdicional democrático, Curitiba: Juruá, 2008, especialmente, $\mathrm{n}^{\circ}$ 7, pp. 201 y ss.

26 Derecho y processo, Op. cit., n 53, p. 104.

27 Esa idea hoy está muy presente en el derecho brasileño. Ya en 1990, ADA PELLEGRINI GRINOVER, identificaba el procedimiento con "um processo jurisdicional de estrutura cooperatória”, As garantias constitucionais do processo. In: Novas Tendências do Direito Processual, Rio de Janeiro: Forense Universitária, 1990, p. 02. Modernamente esta visión se difundió bastante, como podemos percibir en la obra de DANIEL MITIDIERO, Colaboração no processo civil, São Paulo: RT, 2009 (existe una versión en castellano: Colaboración en el proceso civil, Lima: Communitas, 2009), FREDIE DIDIER JÚNIOR, Fundamentos do principio 
litis ${ }^{28}$, el principio de contradicción solamente tiene razón de ser si hubiere un conflicto de intereses. Por ello, para Chiovenda, "a demanda judicial existe no momento em que se comunica regularmente à outra parte; nesse momento existe a relação processual" 29 , pues, de lo contrario, como ocurre en la jurisdicción voluntaria, según doctrina dominante, no hay litis, ni partes ${ }^{30}$, visto

da cooperação no direito procesual civil português, Coimbra: Coimbra, 2010 y LORENA MIRANDA SANTOS BARREIROS, Fundamentos constitucionais do principio da cooperação procesual, Salvador: Juspodium, 2013. El desarrollo de esta idea llegó a tal punto que absurdamente el Proyecto del nuevo Código Procesal Civil Brasileño estableció que actor y reo deben cooperar entre sí, conforme explícitamente prevé el art. $6^{\circ}$, según el cual: "Art. $6^{\circ}$ Todos os sujeitos do processo devem cooperar entre sí para que se obtenha, em tempo razoável, decisão de mérito justa e efetiva". Pero contradictoriamente el art. 386 del mismo proyecto establece que la parte tiene "o direito de não producir prova contra si própria". Vale decir, ¿cómo una parte debe colaborar con el juez si tiene el derecho de no producir prueba contra si propia? En el actualísimo Código General del Proceso de Colombia, que entró en vigor en enero de 2014, esta materia está prevista en el art. 78, nº 8, cuando trata de los deberes de las partes y sus apoderados, determinando a ellos: "Prestar al juez su colaboración para la práctica de pruebas $y$ diligencias".

$28 \mathrm{Al}$ que parece, la litis es el concepto que mayor influencia presenta en los institutos procesales, $v$. g., en el concepto de jurisdicción, de relación jurídica, de partes, de sentencia, de cosa juzgada, etc., tanto que CARNELUTTI dice, "en el fondo, todos, más o menos, tenían la intuición de que si no existiese la litis no existiría el proceso civil", Derecho y proceso, Op. cit., $\mathrm{n}^{\circ} 33, \mathrm{p} .63$.

${ }^{29}$ Instituições de direito processual civil, Op. cit., $2^{\circ}$ v., $\mathrm{n}^{\circ} 242$, p. 293. Ese posicionamiento equivocado de Chiovenda que coloca la citación como presupuesto procesal de existencia, vide, otrosí, $1^{\circ}$ v., p. 59, influenció algunos autores brasileños, entre ellos ARRUDA ALVIM, Manual de Direito Processual Civil. São Paulo: RT, 1991, v. I, n 153, p. 302; TERESA ALVIM PINTO, Nulidades da Sentença, São Paulo: RT, 1987, p. 15, a desconsideraren el art. 263 del CPC Brasileño, que solamente exige para la existencia de la relación procesal una demanda propuesta delante de un órgano dotado de jurisdicción, como muy bien esclarece JORGE L. DALL'AGNOL, Pressupostos Processuais, Porto Alegre: LEJUR, 1988, especialmente en el no 2.2, p. 33; ARAKEN ASSIS, Cumulação de Ações, São Paulo: RT, 1989, n 5.6, p. 37 y GALENO LACERDA, Despacho Saneador, Porto Alegre: Sergio Fabris, 1985, p. 75.

30 En ese sentido, en el Brasil, tenemos ARRUDA ALVIM, Op. cit., nº 57, p. 111; FREDERICO MARQUES, Manual de Direito Processual Civil, São Paulo: Saraiva, 1990, n 62, p. 89; LOPES DA COSTA, Direito Processual Civil Brasileiro, Rio de Janeiro: J. Konfino, 1946, n 116 e 117, p. 160-1; MOACYR A. SANTOS, Primeira Linhas de Direito Processual Civil, São Paulo: Saraiva, 1990, $1^{\circ}$ v., n 53, p. 79; HUMBERTO THEODORO JÚNIOR, Curso de Direito Processual Civil, Rio de Janeiro: Forense, 2007, vol. 1, n 40, p. 44; ERNANE FIDÉLIS, Manual de Direito Processual Civil, São Paulo: Saraiva, 1996, n 21, p. 16. En sentido contrario, EDSON PRATA, Jurisdição voluntária, São Paulo: LEUD, 1979, p. 58. Es interesante notar el posicionamiento de CHIOVENDA, cuando critica los autores que defienden la ausencia de controversia, contenciosidad como característica de la jurisdicción voluntaria, diciendo: "Pode haver processo sem controvérsia (é o que acontece sempre no processo à revelia)", Instituições de direito processual civil, $O p$. cit., $2^{\circ}$ v., p. 18, y más adelante destaca, atribuyendo como característica de la jurisdicción voluntaria la "ausência de duas partes", Op. cit., 2º v., p. 19. 
que la relación procesal presenta solamente un polo, lo que lógicamente hace con que inexista un tratamiento igualitario, porque la igualdad de tratamiento presupone partes antagónicas. Tanto es verdadero que los alemanes tienen un proverbio que dice: "Eines mannes red ist keine red, der richter soll die dell verhoeren beed" (La alegación de un solo hombre no es alegación; el juez debe oír a ambas partes $)^{31}$.

Ese principio confiere el derecho subjetivo a las partes para que puedan ser oídas en juicio. Su objetivación procesal está ubicada en la citación. Por ello, el vicio en la citación es uno de los más graves de todo proceso, vez que ataca directamente el contradictorio y, en el derecho brasileño, jamás puede subsanarse, pudiendo ser atacado a través de la querela nullitatis ${ }^{32}$. Si, por negligencia de la parte, ella no comparecer al juicio, en hipótesis alguna queda violado el principio, pues el contradictorio se establece por la oportunidad de defensa y no por la defensa en sí misma ${ }^{33}$.

A pesar de ciertos principios procesales presentaren, en ciertas circunstancias, excepciones, el contradictorio es absoluto y no admite excepción, debiendo siempre ser respetado, so pena de nulidad del proceso, incluso en el ámbito administrativo, conforme determinación de la propia Constitución Federal, art. $5^{\circ}$, inc. LV, anteriormente citado. Por ser inseparable de la administración de la justicia, constitucionalmente organizada, Winess Millar considera ese principio como "el más destacado de los principios cuestionados" ${ }^{34}$, mientras Calamandrei lo define como "la più pregiata e tipica del processo moderno" 35 . Sin embargo eso no significa decir que el mismo no pueda presentarse en el proceso de forma previa, diferida o eventual, como más adelante analizaremos.

31 WYNESS MILLAR, Op. cit., p. 47.

32 Sobre el origen de la querela nullitatis y su desarrollo en la doctrina, consultar fundamentalmente CALAMANDREI, La casación civil, Buenos Aires: Editorial Bibliográfica Argentina, 1945, t. I, v. 1, cap. III, p. 161 hasta 176, y en el derecho brasileño OVÍDIO B. DA SILVA, Sobrevivência da 'querela nullitatis'. In: Da Sentença Liminar à Nulidade da Sentença, Rio de Janeiro: Forense, 2001, p. 81 hasta 92.

33 También en ese diapasón, LINO PALACIO, para quien el contradictorio "no exige la efectividad del ejercicio de tal derecho, razón por la cual éste no puede invocarse cuando la parte interesada no lo hizo valer, por omisión o negligencia, los medios de defensa, pruebas o recursos de que dispuso en su momento", Manual de derecho procesal civil, Buenos Aires: Abeledo Perrot, $17^{\text {a }}$ ed., 2003, no 27, p. 66. Igualmente JORGE PEYRANO, para quien "el proceso contumacial, en cambio, no es un caso de restricción del contradictorio, sino un supuesto de no aprovechamiento de la oportunidad de ser oído que otorga aquél", Op. cit., p. 156.

34 Op. cit., p. 47.

35 Processo e Democrazia. In: Opere Giuridiche. Napoli: Morano, 1965, v. 1, p. 681. 
Cumple resaltar, finalmente, que el contradictorio se establece entre las partes en el proceso y no con el juez. Ese fue el principal argumento utilizado por el Supremo Tribunal Federal por ocasión del juzgamiento de la Acción Directa de Inconstitucionalidad - ADI 1.105-7/DF, para declarar la inconstitucionalidad del n ${ }^{\circ}$ IX del artículo 7. ${ }^{\circ}$ de la Ley 8.906/94 (Estatuto de la Abogacía y el Colegio de Abogados de Brasil) ${ }^{36}$.

\section{ESPECIES DE CONTRADICTORIO}

Durante los años de desarrollo del estudio de ese principio, su aplicación fue encontrando diversas formas de realización hasta el punto de presentarse, actualmente, una clasificación de dicho principio en previo, diferido o eventual.

En la primera hipótesis, previo, el contradictorio presentase en su acepción clásica, audiatur et altera pars, vale decir, el juez oye ambas las partes para, posteriormente, decidir, como suele ocurrir en todos los procesos.

En el caso de ser diferido el contradictorio, el juez primero decide, asegurando el bien de la vida, para solamente después realizarlo, como puede ocurrir, por ejemplo, en la adopción de una medida cautelar inaudita altera parte, o sea, el juez adopta la medida cautelar sin oír, inicialmente, el demandado, postergando, así, el contradictorio para el momento siguiente ${ }^{37}$.

En la última hipótesis, eventual, el contradictorio solamente ocurrirá si el interesado proponer una demanda para ampliar o finalizar la cognición realizada en el proceso anterior, o sea, el contradictorio irá ocurrir en otro proceso en la eventualidad del interesado así lo requerir, como irá ocurrir en el instituto conocido en el derecho brasileño como estabilidad de la tutela anticipada

36 En el mismo sentido es el juzgamiento de la ADI 1.127, rel. p/ac. Min. Ricardo Lewandowski, j. 17.5.2006, plenário, DJE 11.6.2010, según el cual “a sustentação oral pelo advogado, após o voto do Relator, afronta o devido processo legal, além de poder causar tumulto processual, uma vez que o contraditório se estabelece entre as partes". En sentido contrario, entendiendo que el contradictorio también se establece con el juez, MARINONI y MITIDIERO, cuando afirman que "o juiz encontra-se igualmente sujeito ao contraditório", Curso de direito constitucional, RT, 2012, p. 648. La justicia común, por su vez, sigue el modelo apuntado por la Corte Suprema, pues el abogado, delante del tribunal, solamente puede hablar antes del voto del juez relator, mientras que en la justicia laboral el abogado habla después del voto del juez relator. Este punto de vista será mejor desarrollado más adelante dentro de la fase constitucional.

37 Para JORGE PEYRANO, esas situaciones "no son excepciones al contradictorio, sino meras restricciones temporales a su vigencia”, Op. cit., p. 155. 
satisfactiva, hoy comprehendida en el art. 305 del proyecto del nuevo Código Procesal Civil ${ }^{38}$.

\section{LA EVOLUCIÓN DEL PRINCIPIO: DE LA FASE FORMAL A LA CONSTITUCIONAL}

El contradictorio, en mi opinión, puede ser más bien comprehendido levándose en consideración su desarrollo a través de los tiempos, vale decir, a lo largo de tres fases distintas. La primera, que denomino formal y está caracterizada por la necesidad de informar; la segunda, material que caracterizase por la posibilidad de participación y la tercera, constitucional, identificada por el derecho de influenciar.

\subsection{Las fases formal y material}

La primera y segunda fase son bien conocidas y pueden ser identificadas a través de ese tropo: el contradictorio es como una moneda que presenta, en uno de los lados, la necesidad de informar y, en el otro, la posibilidad de participación ${ }^{39}$. La suma de ese binomio designa, para COUTURE, las garantías del due process of law, pues, según él, es necesario que: " a) el demandado haya tenido debida

38 "Art. 305. A tutela antecipada satisfativa, concedida nos termos do art. 304, torna-se estável se da decisão que a conceder não for interposto o respectivo recurso. $\$ 1^{\circ}$ No caso previsto no caput, o processo será extinto. $\$ 2^{\circ}$ Qualquer das partes poderá demandar a outra com o intuito de rever, reformar ou invalidar a tutela antecipada satisfativa estabilizada nos termos do caput. $\mathbb{S} 3^{\circ}$ A tutela antecipada satisfativa conservará seus efeitos, enquanto não revista, reformada ou invalidada por decisão de mérito proferida na ação de que trata o $\mathbb{S} 2^{\circ} . \mathbb{S} 4^{\circ}$ Qualquer das partes poderá requerer o desarquivamento dos autos em que foi concedida a medida, para instruir a petição inicial da ação a que se refere o $\mathbb{S} 2^{\circ}$, prevento $o$ juízo em que a tutela satisfativa foi concedida. $\$ 5^{\circ} \mathrm{O}$ direito de rever, reformar ou invalidar a tutela antecipada, previsto no $\mathbb{2} 2^{\circ}$ deste artigo, extingue-se após dois anos, contados da ciência da decisão que extinguiu o processo, nos termos do $\$ 1^{\circ}$ ". Sobre el tema consultar, en castellano, el estudio de JOSÉ ROBERTO BEDAQUE que hace una trayectoria histórica del instituto apuntando justificativas, pues, según el autor: "Lo que se pretende, por razones eminentemente pragmáticas - pero no destituidas de análisis teórico- es dejar que las propias partes decidan sobre la conveniencia o no, de la instauración del procedimiento de la demanda y su definición en términos tradicionales, con actividades instructorias de las partes y cognición previa y completa del juez con la correspondiente sentencia de mérito", "Estabilización de la tutela anticipada". In: Estudios sobre las medidas cautelares. Coord. Renzo Cavani Brain. Lima: Normas Legales, 2010, p. 241.

39 Esta visión formal y material del contradictorio, según destaca PROTO PISANI, está vinculada "alla ideologia liberale" y, mientras "frutto di una concezione liberal-individualistica della realtà presuppone che all'eguaglianza formale delle parti corrisponda l'eguaglianza sostanziale", Lezioni di diritto processuale civile, Napoli: Jovene, 1996, p. 224. 
noticia, la que puede ser actual o implícita; b) que se le haya dado una razonable oportunidad de comparecer y exponer sus derechos"40.

La redacción de ese principio contenida en varios códigos procesales remonta a esta fase, pese el valor de la doctrina que insistentemente tiene direccionado sus esfuerzos para ampliar su alcance. Entre las legislaciones extranjeras, podemos citar el art. 101 del Codice di Procedura Civile Italiano ${ }^{41}$, el art. 278, III, de la ZPO alemana ${ }^{42}$, bien como el art. 16 do Nouveau Code de Procédure Civile Francés ${ }^{43}$, y los arts. $171^{44}$ y $133, n^{\circ} 5^{45}$ y $8^{46}$ del actualísimo Código General del Proceso de Colombia, entre otras.

\subsection{La fase constitucional}

La tercera y actual fase, que denomino constitucional y está reconocida en el derecho de influenciar, o, como quiere N. TROCKER, en el "princpio di partecipazione" ${ }^{\prime 7}$, puede ser bien aprehendida por medio de las decisiones

40 Fundamentos del derecho procesal civil, Op. cit., p. 150 También en ese sentido y con mucha profundidad DINAMARCO, "O princípio do contraditório e sua dupla destinação". In: Fundamentos do Processo Civil Moderno, São Paulo: Malheiros, $5^{\mathrm{a}}$ ed., 2002, p. 124 y s; NELSON NERY JUNIOR, Princípios do Processo Civil na Constituição Federal, Op. cit., p. 222 y ADA PELLEGRINI GRINOVER, “O conteúdo da garantia do contraditório”. In: Novas Tendências do Direito Processual, Op. cit., p. 17 e 18.

41 "Il giudice, salvo che la legge disponga altrimenti, non può statuire sopra alcuna domanda, se la parte contro la quale è proposta non è stata regolarmente citata e non è comparsa".

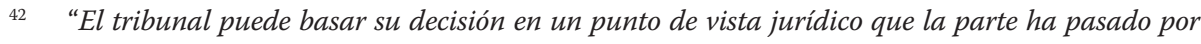
alto de forma perceptible o ha considerado irrelevante, en cuanto no se refiera únicamente a una reclamación de orden accesorio, sólo si ha dado ocasión para la declaración sobre él", Código Procesal Civil Alemán. Trad. Emilio Eiranova Encinas. Madrid: Marcial Pons, 2001, p. 83.

43 "Le juge doit, en toutes circonstances, faire observer et observer lui-même le principe de la contradiction. Il ne peut retenir, dans sa décision, les moyens, les explications et les documents invoqués ou produits par les parties que si celles-ci ont été à même d'en débattre contradictoirement. Il ne peut fonder sa décision sur les moyens de droit qu'il a relevés d'office sans avoir au préalable invité les parties à présenter leurs observations".

44 "Artículo 171. Juez que debe practicar las pruebas. El juez practicará personalmente todas las pruebas. Si no lo pudiere hacer por razón de territorio o por otras causas, podrá hacerlo a través de videoconferencia, teleconferencia o de cualquier otro medio de comunicación que garantice la inmediación, concentración y contradicción".

$45 \quad$ El proceso será nulo: "5. Cuando se omiten las oportunidades para solicitar, decretar o practicar pruebas, o cuando se omite la práctica de una prueba que de acuerdo con la ley sea obligatoria".

46 El proceso será nulo: "8. Cuando no se practica en legal forma la notificación del auto admisorio de la demanda a personas determinadas, (...)".

47 Processo civile e costituzione: problemi di diritto tedesco e italiano, Op. cit., cap. VI, p. 371. 
del Tribunal Constitucional Federal Alemán (Bundesverfassungsgericht), en especial esta, según la cual: "Essa oitiva é, assim, primeiramente, pressuposto de uma decisão correta. Além disso, a dignidade da pessoa exige que não se disponha sobre seu direito de maneira leviana, com base [somente] na autoridade [estatal]: o indivíduo não só deve ser o objeto da decisão do juiz, como deve ser ouvido antes de uma decisão que envolva seus direitos, a fim de poder ter influência sobre o processo e o seu resultado (BVerfGE 7, 53 [57]; 7, 275 [279]" 48 (subrayas fuera de texto).

A partir de la reiterada jurisprudencia del Tribunal Constitucional Federal Alemán, la doctrina, en los más diversos países, pasó a ampliar significativamente ese principio ${ }^{49}$. Esa garantía constitucional de poder influenciar significa, en las palabras de Antonio Cabral, "qualquer condicionamento significativo à conduta dos demais sujeitos do processo, realizado a partir de posições críticas ou omissões conclusivas, transmitidas comunicativamente e que, caso não existissem, poderiam, mantidas as demais condições, motivar o sujeito condicionado a agir de modo diverso" ${ }^{\text {" }}$.

Existe mayor proximidad del principio de contradicción con el principio dispositivo ${ }^{51}$, y no lo dispensa en aquellos procesos con acentuada carga de inquisitorio ${ }^{52}$. En ese sentido ya se manifestó la Corte di Cassazione de Italia, al reconocer que "la procedibilità ex officio (...) non esclude l'esigenza della tutela del diritto di difesa dei soggetti interessati e, como mezzo a fine, dell'attuazione del contraddittorio" ${ }^{53}$.

48 Cinquenta Anos de Jurisprudência do Tribunal Constitucional Federal Alemão. Org. Leonardo Martins. Trad. Beatriz Hennig y otros. Montevideo: Fundación Konrad-Adenauer, 2005, $\$ 34$, p. 915.

49 Sobre el tema, consultar obligatoriamente el excelente artículo de ANTONIO CABRAL, Il principio del contraddittorio come diritto d'influenza e dovere di dibattito. In: Rivista di Diritto Processuale, Anno LX, n² 2, aprile-giugno, p. 453 y s.

50 Nulidades no processo moderno: contraditório, influência e validade 'prima facie' dos atos processuais, Rio de janeiro: Forense, $2^{\mathrm{a}}$ ed., 2010, p. 114.

51 Conforme PEYRANO, Op. cit., p. 148 e JOSÉ M.R.TESHEINER, Elementos para uma Teoria Geral do Processo. São Paulo: Saraiva, 1993, p. 41.

52 Concuerdan con ese entendimiento V. DENTI, Perizie, nullità processuali e contraddittorio, in Rivista di Diritto Processuale, 1967, p. 395 y s; CAPPELLETTI, La testimonianza della parte nel sistema dell'oralità. Milano: Giuffrè, 1962, v. I, p. 352, nota 30 y N. TROCKER, Processo Civile e Constituzione: problemi di diritto tedesco e italiano. Milano: Giuffré, 1974, pp. 373 - 379.

53 Apud N. TROCKER, Processo Civile e Constituzione, Op. cit., p. 387, nota de pie 38. 
Es cierto que el derecho constitucional de acción y de defensa ya no pueden más ser estudiados y aplicados sin la debida correspondencia con el principio constitucional de contradicción, razón por la cual esta tríade constitucional puede ser resumida, en las palabras de Martinetto, "nella costante possibilità di partecipare attivamente allo svolgimento del processo cooperando sia alla ricerca dei fatti ed alla raccolta delle prove, sia alla elaborazione e formazione del convincimento del giudice" ${ }^{\text {54 }}$.

Parece oportuno, sobre el particular, analizar de manera concreta cuando el principio de contradicción será más efectivo, vale decir, cuando él realmente cumple su papel de interferir en la decisión, en el resultado del recurso, levándose en consideración la realidad hoy vivida en los tribunales brasileños. ¿Será más efectivo si realizado antes o después del voto del juez-relator del recurso en el tribunal ${ }^{55}$ ? Teóricamente será más eficaz si realizado antes del juzgamiento proferido por el juez-relator, pues así concretamente el abogado cuando hable oralmente delante del tribunal podrá influenciar la decisión del juez-relator. Pero, en realidad, la decisión ya está hecha mucho antes del juzgamiento ser realizado. De ahí que algunos tribunales, especialmente el Tribunal Regional Laboral, en Rio Grande del Sur, permitan que los abogados hagan su defensa oral después del 'voto' del juez-relator, eso es, el abogado habla y contesta todos los argumentos utilizados por el juez-relator en su decisión, permitiendo así una interferencia mayor en el destino del recurso, ya que conoce los argumentos que fueron utilizados para rechazar el recurso, pudiendo así, incluso, convencer los demás jueces que participan del juzgamiento.

Por todo eso, el proceso hoy solamente puede ser comprehendido dentro de su dimensión democrática, como un espacio público para los debates ${ }^{56}$, razón por la cual conceptuamos proceso actualmente como 'un espacio

54 Contraddittorio (Principio del). In: Novissimo Digesto Italiano, Torino: Utet, 1959, vol. IV, p. 460

55 De acuerdo con la Ley Interna del Tribunal de Justicia del Rio Grande del Sur, art 17, el órgano encargado de juzgar la apelación se llama 'Cámara' y es compuesta por cuatro jueces, siendo que solamente tres participarán del juzgamiento. Uno de ellos, el denominado 'relator', art. 169, es el encargado de leer el recurso y dictar primero su 'voto' (las decisiones de los jueces en el tribunal se llaman 'voto'). En el derecho brasileño el 'relator' primero hace un resumen de todo el proceso, después el abogado hace su defensa oralmente, luego a seguir el 'relator' lee su decisión, para, finalmente, los dos otros jueces decidieren.

56 Por espacio o esfera pública debemos comprehender, según HABERMAS, el siguiente: " $A$ esfera pública constitui principalmente uma 'estrutura comunicacional' do agir orientado pelo entendimento, a qual tem a ver com o 'espaço social' gerado no agir comunicativo, não com as 'funções' nem com o 'conteúdo' da comunicação cotidiana', Direito e Democracia: entre 
discursivo intersubjetivo de indole pública y política, en la búsqueda de valores socialmente relevantes y que solamente puede ser comprehendido en una perspectiva constitucionalmente dialógica entre los varios sujetos envueltos'.

En definitivo, podemos concluir con Trocker que el contradictorio, modernamente, dejó de ser puramente "la difesa intesa in senso negativo" y pasó a significar la "influenza intesa come 'Mitwirkungsbefugnis' (ZEUNER) o 'Einwirkungsmöglichkeit' (BAUR), ossia come diritto o possibilità di incidere attivamente sullo svolgimento e sull'esito del giudizio" ${ }^{57}$.

\section{LOS REFLEJOS DEL PRINCIPIO EN EL DERECHO PROBATORIO BRASILEÑO}

La prueba, como es sabido, está umbilicalmente ligada al principio de contradicción, razón por la cual su precisa comprensión exige, en ese momento, un análisis mayor ${ }^{58}$.

El contradictorio es condición de validez de las pruebas, porque toda y cualquier actividad instructoria tiene que ser producida en contradicción, razón por la cual sobrelleva el principio de inmediación, pues, segundo Isidoro Eisner, la inmediación es: "el principio en virtud del cual se procura asegurar que el juezo tribunal se halle en permanente e intima vinculación personal con los sujetos y elementos que intervienen en el proceso, recibiendo directamente las alegaciones de las partes y las aportaciones probatorias; a fin de que pueda conocer en toda su significación el material de la causa, desde el principio de ella, quien a su término ha de pronunciar la sentencia que la resuelva"59. Esa inmediación existe

facticidade e validade. Trad. Flavio Beno Siebeneichler. Rio de Janeiro: Tempo Brasileiro, 1997, v. II, p. 92.

Processo civile e costituzione: problemi di diritto tedesco e italiano, Op. cit., cap. VI, p. 371.

58 Sobre el principio del contradictorio, consultar mi escrito en Provas Atípicas, Porto Alegre: Livraria do Advogado, 1998, p. 30 a 35. Para mejor profundizar las matrices histórico-culturales del contradictorio, ver por todos PICARDI, Audiatur et altera pars: as matrizes histórico-culturais do contraditório. In: Jurisdição e Processo. Rio de Janeiro: Forense, 2008, p. 127 a 143.

59 La inmediación en el proceso, Buenos Aires: Depalma, 1963, n 32, p. 33. Sobre el tema consultar obligatoriamente el artículo de PEREIRA CAMPOS, SANTIAGO, Mecanismos legales para garantizar la efectiva aplicación del principio de inmediación en el proceso por audiencias. In: Modernización de la Justicia Civil. Coord. por Santiago Pereira Campos. Montevideo: Universidad de Montevideo, 2011, p. 265 a 294 y JORGE PEYRANO,

Nuevas tácticas procesales, Rosario: Nova Tesis, $2010, \$ 6^{\circ}$, p. 59 y s, especialmente, p. 73 hasta 81. 
tanto de las partes en relación al juez como del juez en relación a las partes. En el primer caso, la prueba es inválida sin la presencia de las partes; es lo que los alemanes llaman de Parteiöffentlichkeit ${ }^{60}$, pues, si el magistrado, mismo de oficio, recoger la prueba y no comunicar a las partes para que efectivamente ellas puedan influéncialo, esa prueba está manchada, eso es, inválida para producir efectos objetivos sobre la sentencia ${ }^{61}$, ejemplo, la inspección ocular. En la segunda hipótesis, esclarece Trocker que "la assunzione delle prove deve avvenire davanti all'organo giudicante" 62 , so pena de ser considerada inválida, en la medida en que el magistrado es el destinatario directo de la prueba; y, por el criterio subjetivo, es él quien deberá formar su convicción interior, que solamente podrá ser adquirida mediante la percepción ${ }^{63}$, conforme art. 131 del actual Código Procesal Civil ${ }^{64} \mathrm{y}$ art. 378 del proyecto del nuevo $\mathrm{CPC}^{65}$. De ahí concluir Ada Pellegrini Grinover que "tanto será viciada a prova que for colhida sem a presença do juiz, como o será a prova que for colhida pelo juiz, sem a presença das partes" 6 .

60 N. TROCKER, Processo Civile e Constituzione, Op. cit., p. 553.

${ }_{61}$ En ese sentido, citando jurisprudencia de los tribunales alemanes, N. TROCKER, Processo Civile e Constituzione, Op. cit., p. 536, nota 40 y ADA PELLEGRINI GRINOVER, O conteúdo da garantia do contraditório, Op. cit., p. 24. La Ley de Enjuiciamiento civil Española 1/2000 establece regla expresa respecto al tema en el art. 289, que dice literalmente: "Las pruebas se practicarán contradictoriamente en vista pública, o con publicidad y documentación similares si no se llevasen a efecto en la sede del tribunal". En igual sentido, el art. 415, 1, del CPC Portugués que dice: "Salvo disposição em contrário, não são admitidas nem produzidas provas sem audiência contraditória da parte a quem hajam de ser opostas".

En cierta medida el actualísimo Código General del Proceso de Colombia, de 2012, vincula la prueba al debido proceso legal en su art. 14, cuando afirma: “(...) Es nula de pleno derecho la prueba obtenida con violación del debido proceso".

62 Op. cit., p. 548. En igual sentido, ADA PELLEGRINI, O conteúdo da garantia do contraditório, Op. cit., p. 22 e s.

63 De igual modo MALATESTA, cuando afirma "Así como las facultades de la percepción son las fuentes subjetivas de la certeza, así las pruebas son el modo de manifestación de la fuente objetiva que es la verdad", Lógica de las pruebas en materia criminal. Buenos Aires: General Lavalle, 1945, p. 71. Apuntando una enormidad de autores alemanes que sostienen que la percepción es la única vía para la prueba de los hechos, CARNELUTTI, La Prueba Civil. Buenos Aires: Arayú, 1955, p. 53, nota 74, que indica Stein como uno de los más destacados, por cuanto el autor alemán afirma que: "La percepción es la única vía para la prueba de los hechos", Op. cit., p. 53, nota 74.

64 "Art. 131. O juiz apreciará livremente a prova, atendendo aos fatos e circunstâncias constantes dos autos, ainda que não alegados pelas partes; mas deverá indicar, na sentença, os motivos que Ihe formaram o convencimento".

${ }_{65}$ "Art. 378. O juiz apreciará a prova constante dos autos, independentemente do sujeito que a tiver promovido, e indicará na decisão as razões da formação de seu convencimento".

66 O conteúdo da garantia do contraditório, Op. cit., p. 22. 
Cumple destacar en ese momento la distinción entre el principio de contradicción y de la amplia defensa, que la propia Constitución hace, pues, entre un principio y otro, utiliza la conjunción copulativa "y", que sugiere suma, acrecimos ${ }^{67}$. En el proceso civil, no existe amplia defensa, solamente en el proceso penal, pues en ese tenemos la defensa considerada técnica y la defensa considerada personal. La defensa técnica es aquella hecha por profesional legalmente habilitado, según el art. 263 del Código Procesal Penal ${ }^{68}$, y, mismo que el acusado no la quiera, el Estado está obligado a asegurarla, es irrenunciable ${ }^{69}$. Con acierto dice Juan Montero Aroca: "Para la sociedad el derecho de éste ser oído es inviolable, para el acusado se trata de un derecho irrenunciable"70. La defensa personal es hecha por el acusado, y esa, por si sola, no tiene gran importancia, pues la propia confesión del acusado no sirve para fundamentar la condenación ${ }^{71}$. Además, los efectos de la rebeldía son contrarios al principio de la amplia defensa. En el proceso civil rige el contradictorio, en la medida en que se puede aplicar la rebeldía, art. 319 do $\mathrm{CPC}^{72}$, bien como la sentencia puede tener como único fundamento la confesión, conforme apartado II, del art. 352 do $\mathrm{CPC}^{73}$.

La importancia del principio de contradicción ya se revela en las normas fundamentales del proceso civil contenidas en el Libro I, Cap. I del proyecto del nuevo CPC, vale decir, de doce (12) normas existentes tres (3) se refieren al

67 Constitución Federal de Brasil, art. 5, LV: "aos litigantes, em processo judicial ou administrativo, e aos acusados em geral são assegurados o contraditório e ampla defesa, com os meios e recursos a ela inerentes". (subrayamos)

68 "Art. 263. Se o acusado não o tiver, ser-lhe-á nomeado defensor pelo juiz, ressalvado o seu direito de, a todo tempo, nomear outro de sua confiança, ou a si mesmo defender-se, caso tenha habilitação. (...)".

69 En ese sentido, JUAN MONTERO AROCA, diciendo que ella es "la verdadera defensa, la técnica, la realizada por abogado es, en general, irrenunciable”, Introducción al derecho procesal, Madrid: Tecnos, 1976, p. 241.

70 Introducción al derecho procesal, Op. cit., p. 241.

71 Ya decidió exactamente en ese sentido el Supremo Tribunal Federal, en el Recurso Criminal $\mathrm{n}^{\circ}$ 91.838, Rel. Min. Soares Muños, in Revista dos Tribunais 540/414 e 415.

72 "Art. 319. Se o réu não contestar a ação, reputar-se-ão verdadeiros os fatos afirmados pelo autor". En igual sentido, el art. 59 y 60 del Código Procesal Civil y Comercial de la Provincia de Buenos Aires. Sobre el tema, consultar obligatoriamente los Comentarios al referido Código de Arazi, Bermejo, De Lázzari, Falcón, Kaminker Oteiza y Rojas, Santa Fe: Rubinzal Culzoni, 2009, v. I, cap. IV, p. 142 hasta 147.

73 Sin correspondencia en el proyecto del nuevo CPC. La ausencia de una ley específica no inviabiliza la afirmación, ya que la confesión, en el proceso civil, aún continúa siendo la reina de las pruebas. 
referido principio ${ }^{74}$, los arts. $7^{75}, 9^{76}$ y $10^{77}$. Esa es la razón por la cual el art. 376 del proyecto del nuevo $\mathrm{CPC}$, no solamente reproduce literalmente el actual art. 332 del CPC, sino que va más allá, destacando incluso la denominada fase constitucional, al afirmar literalmente que: "As partes têm direito de empregar todos os meios legais, bem como os moralmente legítimos, ainda que não especificados neste Código, para provar a verdade dos fatos em que se funda o pedido ou a defesa e influir eficazmente na convicção do juiz" (negrillas fuera de texto).

Considero oportuno destacar ahora, la aplicación de ese principio cuando estamos delante de una prueba documental (clasificada como 'preconstituida') o testifical (clasificada como 'casual', 'constituyenda'), pues las pruebas documentales son esencialmente 'preconstituidas' (Evidence existing before the trial, Vorbereiteter Beweis). Eso equivale decir que un documento, una prueba documental es creada, constituida fuera del proceso, razón por la cual el contradictorio solamente se establece en virtud de la obligatoria comunicación a la parte contraria para, queriendo, impúgnala mediante los mecanismos legales, vale decir, el contradictorio no se establece en el plan de la existencia, en el plan de la creación de la prueba, sino en el plan de la validad de esa en juicio. Jamás una prueba documental será construida dentro del proceso con base en el principio de contradicción, eso ocurre, por obvio, con las pruebas 'casuais' o 'constituendas', es decir, aquellas que son creadas en el curso del proceso, como ocurre, $v$. $g$, con la prueba testifical, y muchas veces con la pericial, etc. En esas el contradictorio acontece exclusivamente en el plan de la existencia, en el plan de la creación de la prueba que es realizada en juicio. Por ello, jamás un juez podrá no aceptar una grabación clandestina con base en la violación del referido principio ${ }^{78}$.

74 Para un análisis más profundado del principio con respecto a la prueba en el proyecto del nuevo CPC, consultar mi escrito en Novo CPC: reflexões e perspectivas. Coord. Antônio Pereira Gaio Júnior y Alexandre Freitas Câmara, Belo Horizonte: Del Rey, 2014, p. 133 hasta 153.

75 “Art. $7^{\circ} \hat{E}$ assegurada às partes paridade de tratamento no curso do processo, competindo ao juiz velar pelo efetivo contraditório".

76 “Art. $9^{\circ}$ Não se proferirá decisão contra uma das partes sem que esta seja previamente ouvida. (..)".

77 “Art. 10. Em qualquer grau de jurisdição, o órgão jurisdicional não pode decidir com base em fundamento a respeito do qual não se tenha oportunizado manifestação das partes, ainda que se trate de matéria apreciável de ofício".

78 Sobre la clasificación de las pruebas, especialmente en preconstituida y casual, consultar mi escrito en Provas Atípicas, Porto Alegre: Livraria do Advogado, 1998, p. 70 y ss., especialmente p. 74. 
En ese exacto sentido, es la redacción del art. 415, 2, del CPC Portugués, que dice: "Quanto às provas constituendas, a parte é notificada, quando não for revel, para todos os atos de preparação e produção da prova, e é admitida a intervir nesses atos nos termos da lei; relativamente às provas pré-constituídas, deve facultar-se à parte a impugnação, tanto da respetiva admissão como da sua força probatória".

\section{REFERENCIAS}

Alvaro De OliVeirA, Carlos Alberto. Do Formalismo no Processo Civil. 3. ed. São Paulo: Saraiva, 2009, 3ª ed., n 14.4, p. 133. , (coord). A"udiatur et altera pars. As matrizes históricos-culturais do contraditório". In: Jurisdição e processo. Trad. por Luís Alberto Reichelt. Rio de Janeiro: Forense, 2008, p. 137.

ÂNGELO MARANINCHI GIANNAKOS, Assistência Judiciária no Direito Brasileiro, Porto Alegre: Livraria do Advogado, 2008.

ANTONIO CABRAL, Il principio del contraddittorio come diritto d'influenza e dovere di dibattito. In: Rivista di Diritto Processuale, Anno LX, n 2, aprile-giugno, p. 453 y s.

ARAKEN ASSIS, Cumulação de Ações, São Paulo: RT, 1989, n 5.6, p. 37

ARRUDA ALVIM, Manual de Direito Processual Civil. São Paulo: RT, 1991, V. I, no 153 , p. 302.

CARNELUTTI, La Prueba Civil. Buenos Aires: Arayú, 1955, p. 53.

, Sistema de derecho procesal civil. Trad. Niceto Alcalá-Zamora y Castillo e Santiago Sentís Melendo. Buenos Aires: Uthea, 1944, v. II, n 124, p. 12.

COUTURE, Eduardo J. Fundamentos del derecho procesal civil. Buenos Aires: Depalma, 1988, p. 183.

DANIEL MITIDIERO, Colaboração no processo civil, São Paulo: RT, 2009.

DIERLE NUNES, Processo jurisdicional democrático, Curitiba: Juruá, 2008, especialmente, $\mathrm{n}^{\circ} 7$, pp. 201 y ss.

FAZZALARI, Elio. "Diffusione del processo e compiti della dottrina”. Rivista Trimestrale di Diritto e Procedura Civile, Milano, Giuffrè, n. 3, 1958, p. 861 e ss.

ERNANE FIDÉLIS, Manual de Direito Processual Civil, São Paulo: Saraiva, 1996, n² 21, p. 16.

EISNER, Principios Procesales. In Revista de Estudios Procesales, nº 4, p. 53. 
FAIRÉN GUILLÉN, El juicio ordinario y los plenarios rápidos. Barcelona: Bosch, 1953, pp. 35 y ss.

FREDIE DIDIER JÚNIOR, Fundamentos do principio da cooperação no direito procesual civil português, Coimbra: Coimbra, 2010.

GALENO LACERDA, Despacho Saneador, Porto Alegre: Sergio Fabris, 1985, p. 75 .

HUMBERTO THEODORO JÚNIOR, Curso de Direito Processual Civil, Rio de Janeiro: Forense, 2007, vol. 1, n 40 , p. 44.

Instituciones del nuevo proceso civil italiano. Trad. de Jaime Guasp. Barcelona: Bosch, 1942, v. I, n 9, p. 34.

JORGE L. DALL'AGNOL, Pressupostos Processuais, Porto Alegre: LEJUR, 1988, p. 33.

JORGE PEYRANO, El Proceso Civil. Buenos Aires: Astrea, 1978, p. 148.

JUAN MONTERO AROCA, Introducción al derecho procesal, Madrid: Tecnos, 1976, p. 241.

LORENA MIRANDA SANTOS BARREIROS, Fundamentos constitucionais do principio da cooperação procesual, Salvador: Juspodium, 2013.

MARCELLO CLARICH, La giustizia. In: Trattato di Diritto Amministrativo. Coord. Sabino Cassese. Milano. Giuffrè, 2003, T. II, nº 2.5.3, p. 2.139.

MERRYMAN, La Tradición Jurídica Romano-Canonica. México: Fondo de Cultura Económica, 1994, p. 78.

MOACYR A. SANTOS, Primeira Linhas de Direito Processual Civil, São Paulo: Saraiva, 1990, $1^{\circ}$ v., n 53, p. 79.

NELSON NERY JUNIOR, Princípios do Processo Civil na Constituição Federal. São Paulo: RT, 2013, p. 255 e 256.

OTHMAR JAUERNIG, Direito Processual Civil. Trad. F. Silveira Ramos. Coimbra: Almedina, 2002, $\$ 29$, p. 167

STEFAN LEIBLE, Proceso Civil Alemán. Trad. Rodolfo E. Witthaus. Colombia: Biblioteca Jurídica Diké e Konrad Adenauer Stiftung, 1999, p. 152 e 153.

TERESA ALVIM PINTO, Nulidades da Sentença, São Paulo: RT, 1987, p. 15.

TROCKER, N. Processo Civile e Constituzione: problemi di diritto tedesco e italiano. Milano: Giuffré, 1974, p. 373 hasta 379.

WYNESS MILLAR, Robert. Los principios formativos del procedimiento civil. Trad. Catalina Grossmann. Buenos Aires: Ediar, 1945, p. 47. 